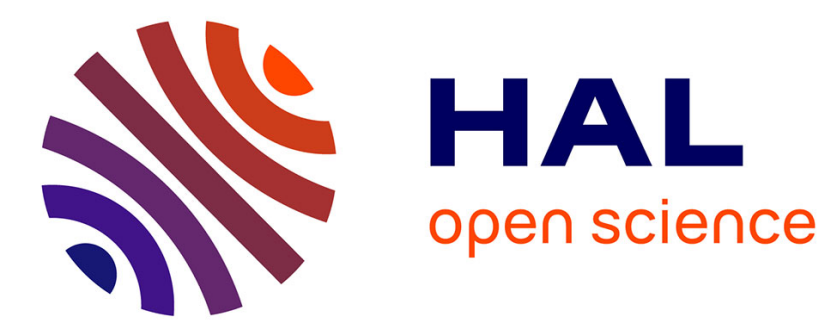

\title{
Experimental and numerical analyses of homogeneity over strip width in roll compaction
}

Abderrahim Michrafy, El. Diarra, John A. Dodds, Mohammed Michrafy

\section{To cite this version:}

Abderrahim Michrafy, El. Diarra, John A. Dodds, Mohammed Michrafy. Experimental and numerical analyses of homogeneity over strip width in roll compaction. Powder Technology, 2011, 206 (1-2, SI), pp.154-160. 10.1016/j.powtec.2010.04.030 . hal-01680751

\section{HAL Id: hal-01680751 https://hal.science/hal-01680751}

Submitted on 6 Sep 2018

HAL is a multi-disciplinary open access archive for the deposit and dissemination of scientific research documents, whether they are published or not. The documents may come from teaching and research institutions in France or abroad, or from public or private research centers.
L'archive ouverte pluridisciplinaire HAL, est destinée au dépôt et à la diffusion de documents scientifiques de niveau recherche, publiés ou non, émanant des établissements d'enseignement et de recherche français ou étrangers, des laboratoires publics ou privés. 


\title{
Experimental and numerical analyses of homogeneity over strip width in roll compaction
}

\author{
A. Michrafy ${ }^{\mathrm{a}, *}$, H. Diarra $^{\mathrm{a}}$, J.A. Dodds ${ }^{\mathrm{a}}$, M. Michrafy ${ }^{\mathrm{b}}$ \\ ${ }^{a}$ RAPSODEE-FRE CNRS 3213, Ecole des Mines d'Albi, Campus Jarlard, 81013 Albi Cedex 09, France \\ b BEM, Bordeaux Management School, 680 cours de la Libération, 33405 Talence, France
}

\begin{abstract}
A B S T R A C T
Homogeneity of properties over the width of strips produced by roll compaction of microcrystalline cellulose powder (MCC) has been examined by light transmission through the compact, by measurements of the porosity distributions and by three-dimensional finite element modeling. Light transmission through compacts revealed periodic heterogeneity in the form of alternate dark and light zones. The period seems to be connected to the geometry of the screw and independent on the feed screw velocity which was varied with the roll speed with a constant ratio. Measurements of the porosity of samples cut from the compacted strip show heterogeneity of the density over the width of strips with a higher density in the centre of the strip and a lower density on the sides.

These two techniques clearly showed the heterogeneous behavior across the width of the compacted strip of MCC. However, the light zones (respectively dark zones) did not correspond to the lower porosity zones (respectively higher porosity zones).

Three-dimensional finite element modeling (FEM) of roll compaction of powders was conducted with two inlet feed conditions: constant feed pressure and constant feed velocity. Results of the simulations using the constant feed pressure show a uniform maximum principal stress and density across the width of the strip. When a constant inlet feed velocity is assumed the maximum principal stress over the strip width was higher at the centre of the strip and decreases to the sides. This profile also corresponds to the density profile over the width of the strip. In this case, the predicted results present a similar tendency to that found by mercury intrusion porosimetery and are in agreement with the measured bulk density of strips produced with different roll speeds.
\end{abstract}

Keywords:

Roll compaction

Heterogeneity of properties

Porous material

3D finite element modeling

\section{Introduction}

Roll compaction is a powder agglomeration process used in variety of industries including the pharmaceutical, mineral and chemical industries. In the pharmaceutical industry, roll compaction is used as a dry granulation method, well suited to powders which are sensitive to water and other solvents. The process can produce composite granules from mixtures of drug substances and excipient powders thus improving flowability, giving more uniform composition and chemical stability for direct compression. Roll compaction of poor flowability powder mixtures requires screw feed of the powder between two counter-rotating rolls. These then draw the powder into the compaction zone and apply a high pressure forming a strip of compacted powder. Despite the simplicity of the roller compaction, a quantitative understanding of the process has proved difficult to develop because of the complexity of the powder behavior and the large number of operating parameters. The heteroge-

\footnotetext{
* Corresponding author.

E-mail address: michrafy@enstimac.fr (A. Michrafy).
}

neity of properties over the compacted strip width is one of the complex features that have been demonstrated in several experimental investigations. Tundermann et al. [1] performed roll compaction of sponge-iron powders MH300 (fine) and MH100, and showed non-uniform density over the strip width with a distribution that depended on the particle size of the powder. Simon and Guigon [2] showed the role of the feed screw on the heterogeneity observed on strips of compacted lactose monohydrate mixed with $4 \%$ coal. In the work of Miguelez-Moran et al. [3,4] on microcrystalline cellulose, characterizations of the density distribution of ribbons of MCC showed a non-homogeneous behavior. However, in the investigations of Lecompte et al. [5] on the roll compaction of organic powder measurements of maximum pressures for several consecutive rotations were practically similar and hence no heterogeneity of the pressure distribution over the strip width was observed. This observation was explained by the fact that the screw was positioned further from the rolls. From the works cited above, it is important to point out the role of the design of roll press, the feeding system, the roll width and the geometry of the screw on the heterogeneity generated over the width of strips of compacted powders. Despite the difficulty in comparing results from the literature due to the type of roll press and to the operating 
conditions, it is commonly accepted that the two main factors responsible for strip heterogeneity are: the powder feed system and the powder flow behavior in the compaction area between rolls.

This paper presents experimental and numerical investigations to analyze the homogeneity of properties over strip width of microcrystalline cellulose powder compacted with a laboratory roll press. Results from the simulations and from the experiments are discussed in terms of the heterogeneity of properties over the width of the strips.

\section{Experimental}

\subsection{Roll press}

Experiments were carried out with a Komarek ${ }^{\circledR}$ B050PH laboratory press with horizontal feed screw. This press was fitted with $100 \mathrm{~mm}$ diameter and $38 \mathrm{~mm}$ wide smooth rolls. Fig. 1 is a schematic diagram of the press. The roll speed can be varied in the range 0-7.5 rpm, the feed screw can be varied in the range $0-137 \mathrm{rpm}$ and the separation force of rolls (known as "hydraulic pressure") can be varied up to $50 \mathrm{kN}$ (corresponding to the linear force $13.2 \mathrm{kN} \mathrm{cm}^{-1}$ ). Two cheek plates are placed on both sides of the rolls as it is shown in Fig. 1.

The upper roll was instrumented with three strain gauges to measure the normal pressure along the width of the roll. The strain gauges were positioned at $10 \mathrm{~mm}$ from the roll surface and are aligned in the direction of the axis (one gauge in the centre and the two others at $5 \mathrm{~mm}$ from both sides of the roll). Thus, there is no direct contact of the sensor with the powder. The signals are transmitted to the computer using a slip ring assembly fixed to the press as it was showed in the picture of Fig. 2.

\subsection{Powder}

Microcrystalline cellulose (MCC) known commercially as Avicel PH102, with a mean particle size $\left(d_{50}\right)$ of $90 \mu \mathrm{m}$, and apparent and true densities of 0.27 and $1.59 \mathrm{~g} / \mathrm{cm}^{3}$, was used in the experiments.

\subsection{Compact and characterization}

It is well known, for roll press with horizontal feeding that screw and roll speeds are the dominant parameters in the roll process. To

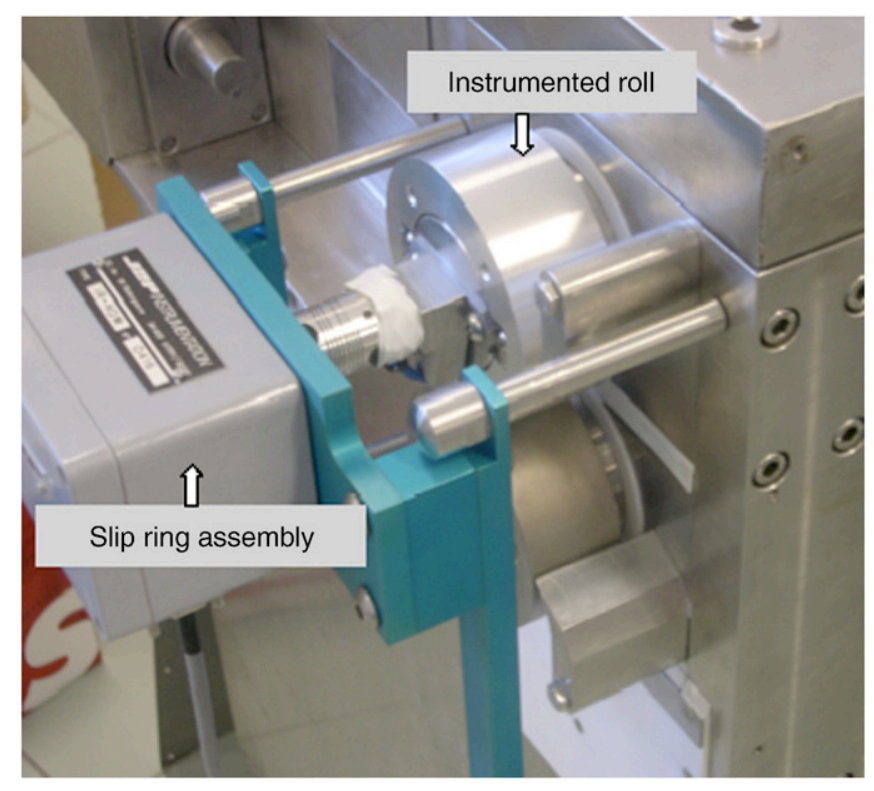

Fig. 2. Picture of instrumented roll and slip ring assembly.

avoid the lack of powder and the overfeeding of powder, the correlation between the screw and roll speeds (Vs and $\mathrm{Vr}$ ) for obtaining a compact with good mechanical properties was first characterized (Fig. 3). Three speed zones were identified: an underfeeding zone where the powder material is not compacted, an overfeeding zone where the machine becomes blocked, and a good compaction zone (giving compact with a good mechanical properties). In this latter zone strips of compacted powder MCC were formed using constant ratio Vs/Vr. The gap was fixed to $2 \mathrm{~mm}$ and a high roll separation force of $34 \mathrm{kN}$ was employed to avoid fluctuations in the thickness of the compacted strip (no fluctuations of the gap). With the above operating conditions and for each pair of screw and roll speeds with $\mathrm{Vs} / \mathrm{Vr}=9.2$, plates of length around $15 \mathrm{~cm}$ were considered and each one was cut into three rectangular pieces. The thickness of samples was in the range $0.19-0.21 \mathrm{~cm}$, the width in $3.5-3.8 \mathrm{~cm}$ and the length in $4-5 \mathrm{~cm}$. The bulk density of the pieces was calculated



Fig. 1. Cross section of the Komarek ${ }^{\circledR}$ B050PH roll press system. 1 - roll, 2 - roll shaft, 3 - bearing block, 4 - supporting hydraulic system, 5 - screw feeder, 6 - screw feeder drive, 7 - feeder barrel, 8 - cheek plate, and 9 - feed hopper. 




Fig. 3. Screw speed vs. roll speed. Zone 1: lack of feeding; Zone 3: overfeeding; Zone 2: good compaction. Line $\mathrm{Vs} / \mathrm{Vr}=9.2$ corresponds to the speeds used to produce strips which bulk density is plotted in Fig. 4 .

from their mass and volume. The density of the plate was evaluated by averaging the three measurements. Results of the averaged density were plotted in Fig. 4 according to the roll speeds. The bulk density evolution showed a decrease for formed strips using roll speeds higher than $6.4 \mathrm{rpm}$. This is generally a consequence of the short residence time of the powder under the pressure.

The analysis of the homogeneity of properties of the strips produced was made in two ways: by light transmission through the compacted strip [2] and by mercury porosimetry measurements of small samples carefully cut from the compacted strip in the rolling and the across directions. The image of the light transmitted through the compact was plotted in Fig. 5 and reveals periodic heterogeneity represented by dark and light zones. The period seems independent on the screw velocity (the roll speed was varied in the good compaction zone without changes of the period size) and seems to be linked to the geometry of the screw.

To aid understanding of the heterogeneity observed, a grid was superimposed according to the alternate lighted and darker zones (Fig. 6). Three groups in the rolling direction of four samples (across the wide) were cut following the plane of the grid. In Fig. 6, the designation G, MG, MD and D corresponds to the position of samples across the width. The symbols " $+\mathrm{S}, \mathrm{S}, \mathrm{C}$ and $+\mathrm{C}$ " correspond respectively to "more dark, dark, clear, and more clear".

With the mercury porosimeter the volume of mercury introduced in each sample at high pressure (up to $30 \mathrm{MPa}$ ) was measured and was used as an index of the porosity of the sample: "the greater the

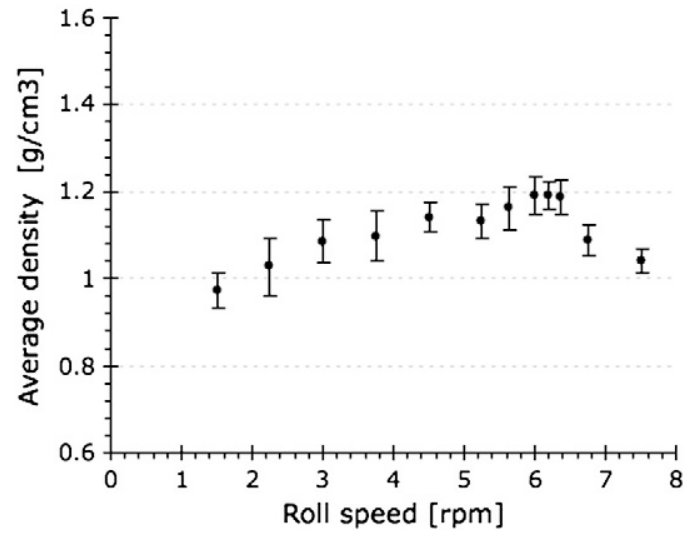

Fig. 4. Average bulk density of compacted strips of MCC according to roll speeds $(\mathrm{Vr}=9.2 \mathrm{Vs})$.

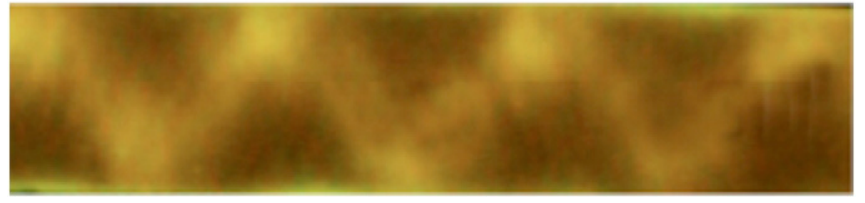

Fig. 5. Results of light transmitted through the compact of microcrystalline cellulose. $\mathrm{Gap}=2 \mathrm{~mm}$, roll speed $=6.4 \mathrm{rpm}$, and screw speed $=59 \mathrm{rpm}$.

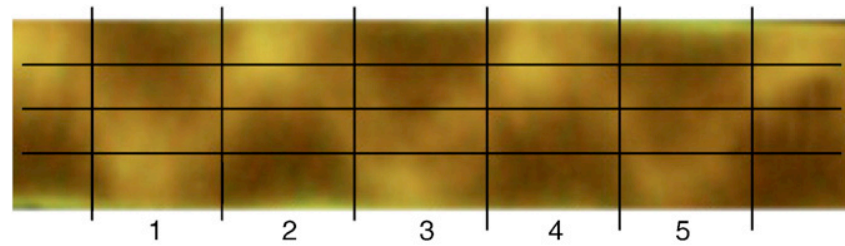

\begin{tabular}{|c|c|c|c|c|}
\hline$G$ & $+S$ & $+C$ & $+S$ & $+C$ \\
\hline$M G$ & $S$ & $C$ & $S$ & $C$ \\
\hline$M D$ & $C$ & $S$ & $C$ & $S$ \\
\hline$D$ & $+C$ & $+S$ & $+C$ & $+S$ \\
\hline
\end{tabular}

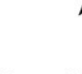

Superimposed grid

Fig. 6. Grid of samples analyzed by mercury porosimeter.

volume introduced, the higher is the porosity of the sample and hence the lower is the density ". Results were plotted in Fig. 7a.

To verify that the intrusion of mercury at high pressure does not introduce errors by modifying the microstructure of samples (e.g. local densification or destruction of internal pores) results at low pressure $(0.1 \mathrm{MPa})$ as plotted in Fig. $7 \mathrm{~b}$ were also examined.
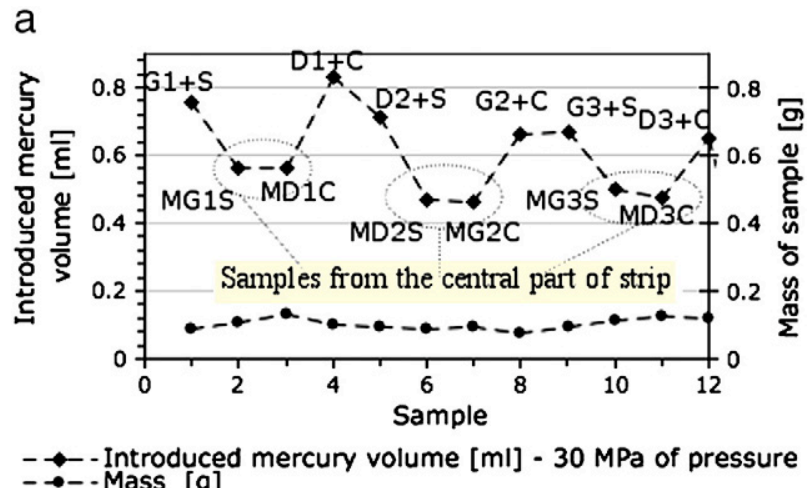

$\mathrm{b}$

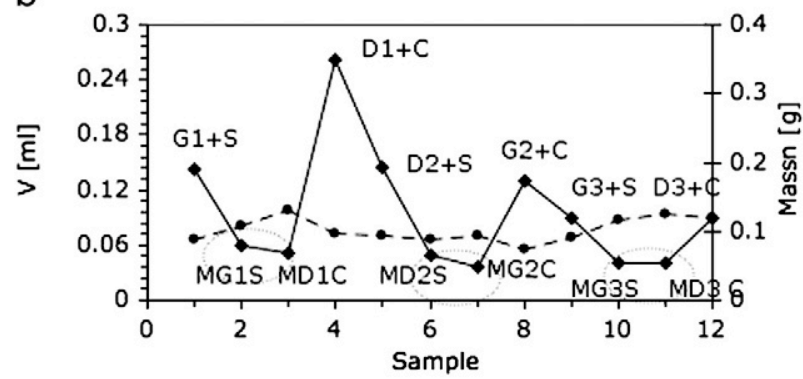

$\longrightarrow$ - Introduced mercury volume $[\mathrm{ml}]-0.1 \mathrm{MPa}$ of pressure

Group of samples cut from the central part of stip

Fig. 7. a. Mercury intrusion porosimetry (pressure $30 \mathrm{MPa}$ ). b. Mercury intrusion porosimetry (pressure $0.1 \mathrm{MPa}$ ). 


\section{Three-dimensional finite element modeling}

The experimental results presented above demonstrate the existence of the heterogeneity of properties over the strip width of compacted MCC powder. This heterogeneity probably results from the non-uniform feeding of powder by the screw, the flow of powders between rolls under the effect of the complex mechanisms of powderroll friction, and the presence of two cheek plates on the roll sides to limit powder loss.

The objective of this section is to use three-dimensional finite element modeling to examine the stress and density distributions over the strip width of compacted MCC powder.

\subsection{Powder behavior}

The analysis was conducted by assuming that the powder behaves as a single phase porous media (without air). As for die compaction [6-10] or for roll compaction in two dimensions [11], the Drucker Prager Cap model implemented in Abaqus ${ }^{\circledR}[12]$ was used. The elastic behavior was assumed to be linear and to depend on the relative density. Results of such modeling depend on the identification of material parameters and the boundary conditions employed. In the space $(p, q)$ "hydrostatic pressure, equivalent stress", the yield surface is essentially represented by the shear surface (shear failure line) and the cap surface. The constitutive equations of the model are voluntarily not listed here and can be found in the references cited above.

The material parameters required by the simulations, and which have to be identified from experiments such instrumented die compaction, simple compression and diametrical compression [9] are: powder cohesion $\mathrm{d}$, internal friction $\beta$ eccentricity of the cap $R$

a

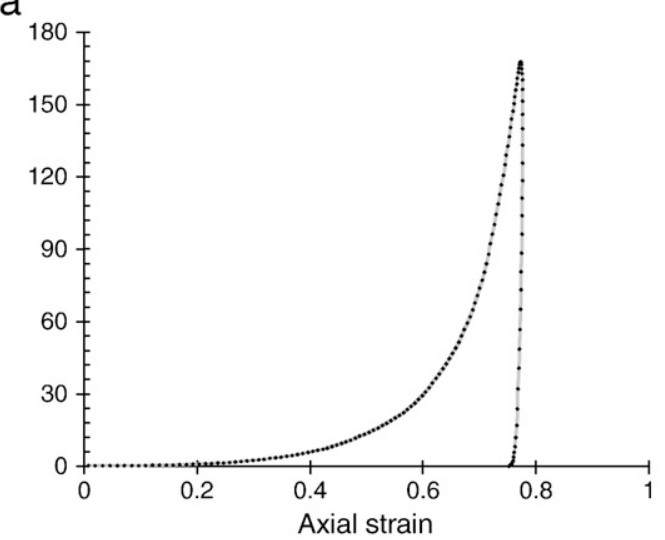

b



Fig. 8. a. Axial stress vs. axial strain of the compression of MCC in a $11.28 \mathrm{~mm}$ diameter of unlubricated die. b. Equivalent stress vs. hydrostatic pressure (cycle loading and unloading of die-compression).
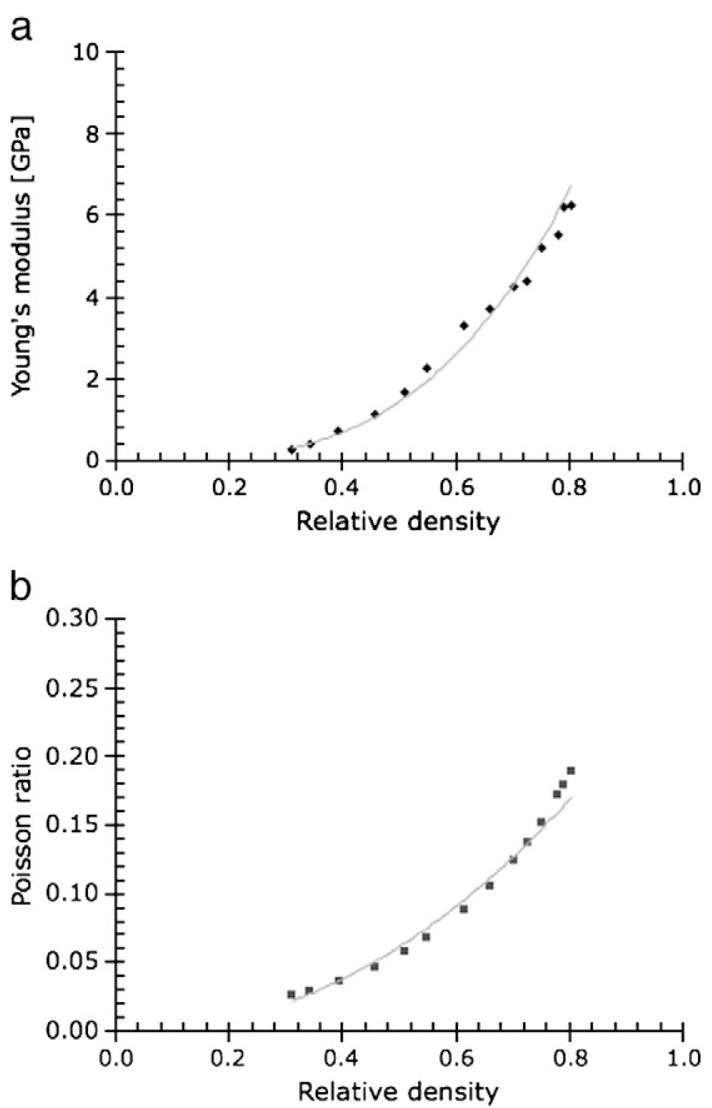

Fig. 9. a. Young's modulus vs. relative density $E\left(\rho_{\mathrm{r}}=1\right)=10.30 \mathrm{GPa}$. b. Poisson's ratio vs. relative density $\nu\left(\rho_{\mathrm{r}}=1\right)=0.28$.

and $P_{\mathrm{b}}$ the evolution of the cap surface according to the volumetric inelastic strain. In the elastic plastic representation used here the relative density is used as variable describing the microstructural state, hence, the parameters cited above and elastic properties depend on this.

\subsection{Calibration of model parameters. Method based on simple tests}

Tablets were prepared by compacting MCC powder in an unlubricated cylindrical die of $11.28 \mathrm{~mm}$ diameter with pressures in the range 20-168 MPa with an instrumented reciprocating press [13]. Axial stresses and displacements of the upper and lower punches $\left(\sigma_{\mathrm{u}}\right.$, $\sigma_{\mathrm{l}}, u_{\mathrm{u}}, u_{\mathrm{l}}$ ), and radial stress $\sigma_{\mathrm{r}}$ on the die were recorded. Fig. 8a and $\mathrm{b}$ shows typical axial stress versus the axial strain and equivalent stress $\left(q=\sigma_{\mathrm{u}}-\sigma_{\mathrm{r}}\right)$ versus hydrostatic pressure $p=\left(\sigma_{\mathrm{u}}+2 \sigma_{\mathrm{r}}\right) / 3$.

\subsubsection{Young modulus and Poisson ratio}

A simple axial compression test was used to evaluate the elastic properties using the tablets prepared as above. The upper and lower punches were lubricated with a magnesium stearate to reduce the role of wall friction. The axial pressure $\sigma_{\mathrm{z}}$ and strain $\varepsilon_{\mathrm{z}}=-\ln \left(h / h_{0}\right)$ and radial (transverse) strain $\varepsilon_{\mathrm{r}}=-\ln \left(d / d_{0}\right)$ were monitored during loading and unloading, ( $h_{0}$ and $d_{0}$ are the initial height and diameter of the tablet). Then, the Young modulus was evaluated from the initial unloading slope of the simple compression curve and the Poisson ratio was given by $v=\frac{-\varepsilon_{r}}{\varepsilon_{z}}$. The resulting changes in elastic properties according to the relative density are plotted in Fig. 9a and b.

\subsubsection{Cohesion and angle of internal friction}

For a given relative density corresponding to a given $\left(p_{\max }, q_{\max }\right)$ of the die compressive cycle (Fig. 8b), the shear failure line of the yield 
surface is defined by two parameters: the cohesion $d$, which is the intersection with the deviatoric axis $q$ and the internal friction angle $\beta$, the slope of the line. They can be identified from the failure stress $\sigma_{\mathrm{d}}$ in the diametrical compression test and the failure stress $\sigma_{\mathrm{u}}$ based on the simple compression test. In the space $(p, q)$ the two resulting points $\left(2 \sigma_{\mathrm{d}} / 3, \sqrt{13} \sigma_{\mathrm{d}}\right)$ and $\left(\sigma_{\mathrm{u}} / 3, \sigma_{\mathrm{u}}\right)$ define the failure line and hence the cohesion and the angle of internal friction. In the range of the relative density studied, the evolution of the cohesion according to the relative density is plotted in Fig. 10a. The angle of internal friction was found in the range $65-71^{\circ}$. These high values are generally obtained because $\sigma_{\mathrm{d}}$ is very low comparatively to $\sigma_{\mathrm{u}}$. Results of internal friction angle are not considered as intrinsic values of the material. They are linked to the test used. To represent internal friction angle of MCC from low to high pressures, the measured high values were associated to high densities and were extended to low densities by decreasing the internal friction angle down to $38^{\circ}$ (internal friction angle of the powder MCC at low pressure using Jenike shear test). The resulting data were plotted in Fig. 10b. It should be noted here that the extension to low pressure is arbitrarily and could not be easily validated with experiment. Similar profiles of the cohesion and the internal friction angle were also proposed in [7].

\subsubsection{Eccentricity and hardening function}

From the fully instrumented die-compression experiment, the maximum stress ( $\left.p_{\max }, q_{\max }\right)$ of the die compressive cycle corresponds to the density reached in the compact. Then, for a given density, the cap surface parameters (the eccentricity $R$ and the cap hardening function $P_{\mathrm{b}}$ ) were calculated from the $\left(p_{\max }, q_{\max }\right)$, the cohesion and the internal friction angle previously obtained [9]. The resulting eccentricity $R$ and hardening function $P_{\mathrm{b}}$ were plotted in Figs. 11 and 12. The above extension of internal friction angle gives an extension of the eccentricity at low densities. This extension has not been experimentally validated and the data of triaxial test of MCC could be useful in this case.

a

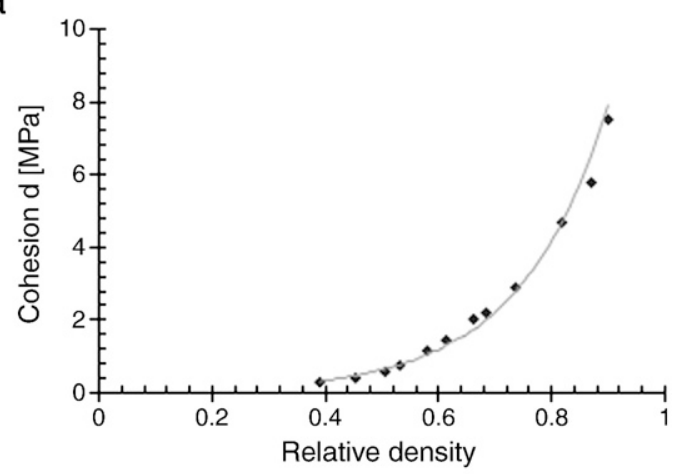

b

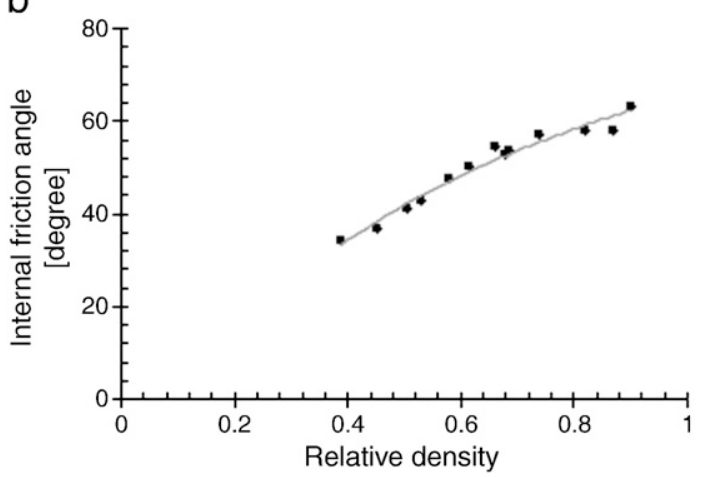

Fig. 10. a. Cohesion vs. relative density. b. Internal friction vs. relative density.

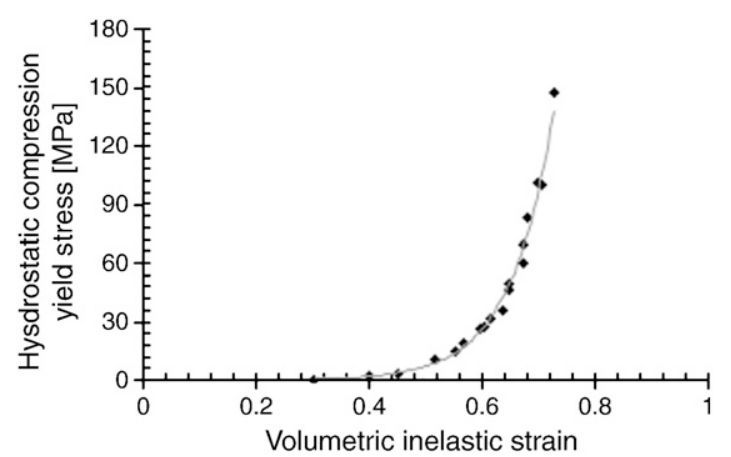

Fig. 11. Hydrostatic yield stress vs. volumetric inelastic strain.

Finally, the resulting evolution of the yield surfaces with relative density and the corresponding die-compression data are plotted in Fig. 13.

\subsubsection{Wall friction}

Coulomb friction was assumed between the rolls and the powder. No instruments were available to measure the tangential force at the contact interface. The friction coefficient was therefore characterized from the die-compaction experiments.

During die compaction, the tangential force to the contact area (die-wall) $F_{\mathrm{t}}=\left(\sigma_{\mathrm{u}}-\sigma_{1}\right) \pi R^{2}$ is proportional to the normal force $F_{\mathrm{r}}=2 \pi R h \sigma_{\mathrm{r}}$. The normal pressure is considered uniform along the compact height $h$.

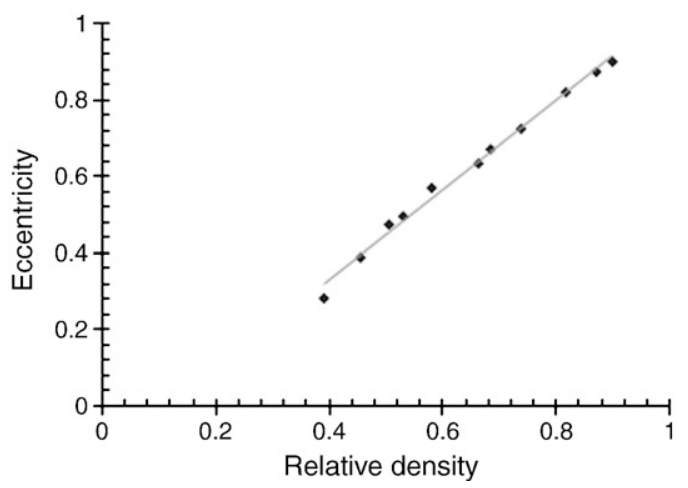

Fig. 12. Eccentricity vs. relative density.



Fig. 13. The evolution of the yield surfaces with the relative density $\rho_{\mathrm{r}}$ of MCC. The dotted lines correspond to the die compressive cycles of MCC. 


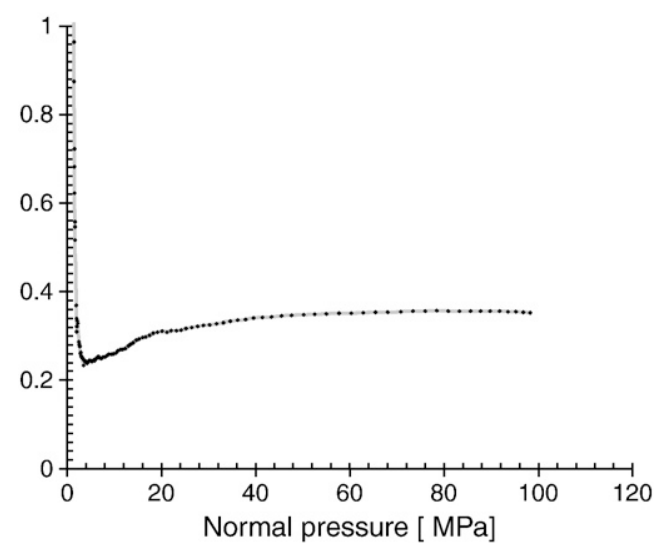

Fig. 14. Die-wall friction coefficient vs. radial pressure of MCC (fitted from Eq. (1)). Data from die compaction in unlubricated die of $11.28 \mathrm{~mm}$ of diameter.

The friction coefficient $\mu\left(\sigma_{\mathrm{r}}\right)$ was then estimated as:

$\mu\left(\sigma_{\mathrm{r}}\right)=\frac{\left(\sigma_{\mathrm{u}}-\sigma_{\mathrm{l}}\right) \pi R^{2}}{2 \pi R h \sigma_{\mathrm{r}}}$

where the height $h$ is obtained from the initial height of the powder bed $(10 \mathrm{~mm})$ and the measured punch displacement $u_{\mathrm{u}}$ and $R=\frac{D}{2}$ with $D=11.28 \mathrm{~mm}$ the internal diameter of the die. Fig. 14 shows the evolution of the wall friction with the normal (radial) pressure in the condition of unlubricated die. As is seen in Fig. 14, the friction coefficient decreases down to 0.24 for low radial pressure $(<5 \mathrm{MPa})$ and increases progressively up to 0.35 .

\subsection{Numerical procedure}

The numerical simulation was performed using commercial software (Abaqus ${ }^{\circledR}$ explicit version 6.5). Behavior is assumed to be symmetrical between rollers and only the upper half of the domain was considered. The roll of $100 \mathrm{~mm}$ of diameter and $38 \mathrm{~mm}$ of width was assumed to be a rigid body. The powder was meshed with 9690 continuum elements C3D8R with reduced integration (Fig. 15). The gap was adjusted to $2.0 \mathrm{~mm}$ and the entry height of the material corresponds to $18^{\circ}$ roll angle. The initial material density was fixed as $0.27 \cdot 10^{3} \mathrm{~kg} / \mathrm{m}^{3}$. Because of the high volume reduction of mesh in the nip zone and the resulting mesh distortion, the Arbitrary Lagrangian Eulerian (ALE) procedure with adaptive meshing was employed with explicit integration using the Abaqus ${ }^{\circledR}$ Explicit code. The powder feed system was approximated by two conditions: uniform feed velocity (equal to the linear velocity of the roll $30 \mathrm{~mm} / \mathrm{s}$ ) and uniform feed pressure (1.0 MPa). Eulerian inflow and outflow boundary conditions were employed to ensure the entry and the exit of the material. For computational efficiency of the quasi-static problem, a mass-scaling factor was used and optimized based on the examination of the level of the kinetic energy that must be without oscillations and be small compared to the internal energy (both elastic and plastic strain energy of the deformable powder material). Coulomb friction was assumed for contact behavior between roll and powder. The friction coefficient was $\mu=0.35$.
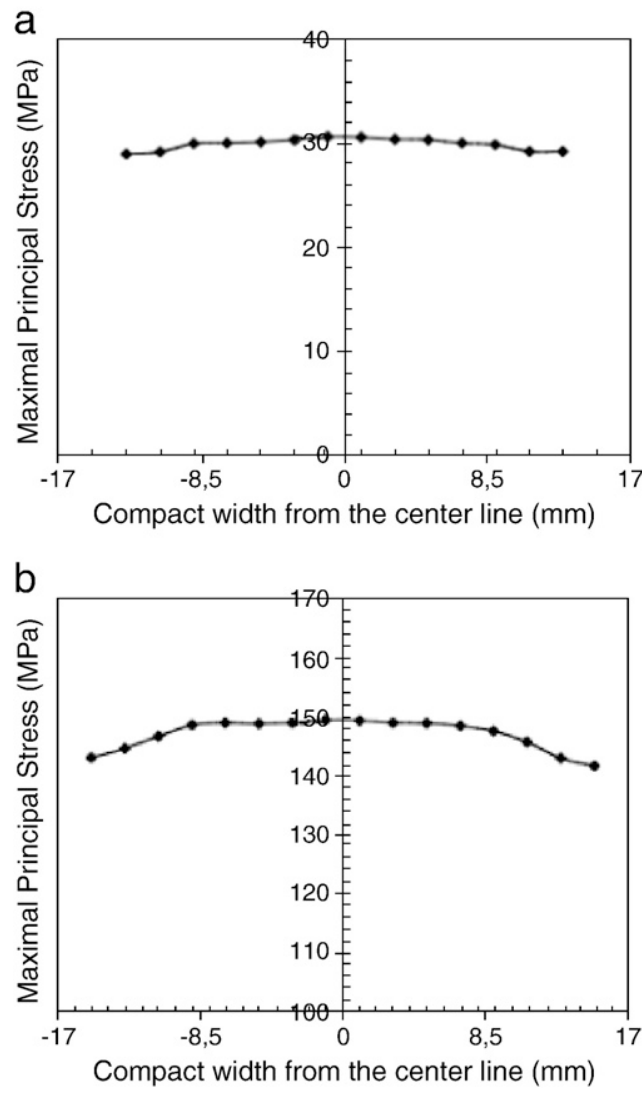

Fig. 16. Distribution of maximum pressure across the width of the strip of MCC. (Predictions at neutral angle position). (a) Boundary conditions with uniform feed pressure. (b) Boundary conditions with uniform feed velocity.

A rigid surface was created in the feed zone to represent the feeder barrel. The presence of this surface avoids the severe distortion of meshes during the feeding. The friction coefficient between the deformable meshes in contact with this surface was fixed to 0 . This condition, which can be physically questionable, ensures a uniform velocity profile in the feeder barrel and hence ensures for the powder, at the entrance between rolls, the same velocity than the linear velocity of the roll. The powder can then flow between the rolls without distortion problems. Also, the cheek plates preventing the powder loss from the sides of the rolls were materialized by null normal displacement.

As the material parameters change with the density, a user subroutine VUMAT was developed to reflect this evolution.

The homogeneity over the strip width was analyzed at the gap position through the distribution of the maximum principal stress (Fig. 16) and the density (Fig. 17) using the above two inlet feed conditions.

\section{Discussion}

As is shown in Fig. 5, the light transmission through compacts reveals a periodic heterogeneity shown by dark and light zones. The analysis of such heterogeneity with different screw velocities showed an identical

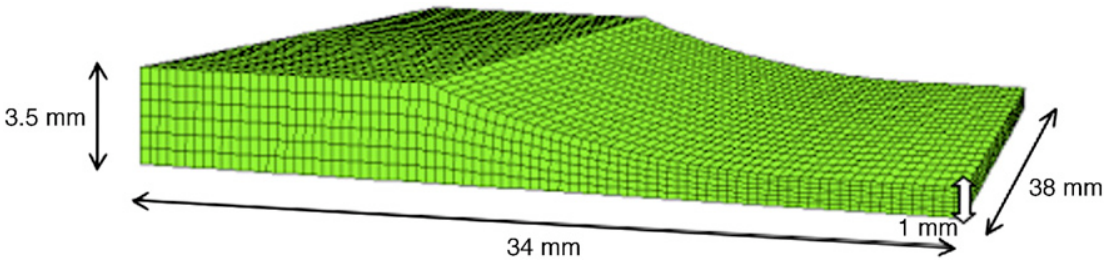

Fig. 15. Meshed domain with continuum elements (C3D8R continuum element with reduced integration - Abaqus $\left.{ }^{\circledR}\right)$. 


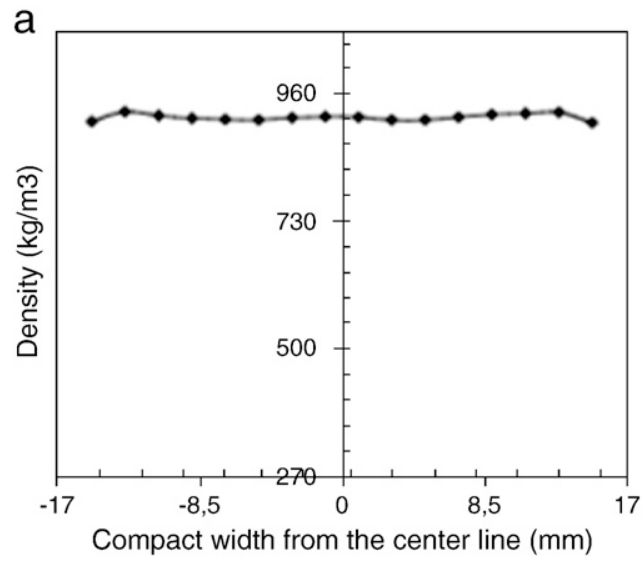

b

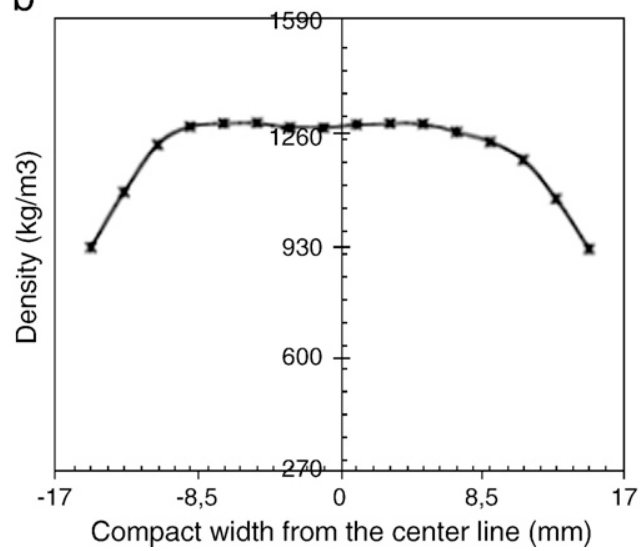

Fig. 17. Density distribution across the width of the strip of MCC. (Predictions at neutral angle position). (a) Predictions using uniform feed pressure condition. (b) Predictions using uniform feed velocity condition.

period connected to the geometry of the screw. Similar results were observed on other powders in the work of Simon and Guigon [2]. According to the above heterogeneity observed over the strip width, and in order to understand if the darker zone (respectively lighter zone) is associated to low densities (respectively higher densities zone), measurements of the porosity of samples cut from the compacted strip following the grid of Fig. 6, were determined by mercury intrusion porosimetry (Fig. 7a and b). These results show the heterogeneity of the porosity over the strip width and indicate that the higher density is in the central part of the strip. This is in agreement with the work of Lecompte et al. [5] and measurements of Miguelez-Moran et al. [3,4]. The weight of the sample used in these measurements is also plotted in Fig. 7a and b, which show little difference in the masses of the samples analyzed. In order to verify that high pressure mercury intrusion does not introduce errors in the measurements by modifying the microstructure of samples (local densification or destruction of internal pores) results obtained at low pressure (0.1 MPa) are plotted in Fig. 7b and also show a similar evolution to the results obtained at high pressure.

The heterogeneity revealed by the light transmission across the width of the strip and the heterogeneity obtained by mercury porosimetry (according to the grid of the Fig. 6) could not be completely correlated. The lighter zones (respectively darker zones) do not correspond to the denser zones (respectively less dense zones). The light transmission results are probably more related to the anisotropy of the microstructure which plays an important role of the light diffusion.

Finally, the two techniques used clearly show that there are heterogeneities across the width of roll compacted strips of MCC. However, questions remain on the effects of the pressure level, the roll width, the powder lubrication of reducing the heterogeneity that could be created by the screw. More investigations in this direction should clarify the impact of these parameters in the homogeneity of strips.

In the three-dimensional FEM (finite element method) simulations of roll compaction, two inlet feed conditions were considered to represent the feed system: a constant feed pressure and a constant feed velocity ensuring a variable entering flux of material. In the case of constant feed pressure, the resulting distribution (over the strip width) of the maximum principal stress and the density on the elements in contact with the roll are approximately uniform (Figs. 16a and 17a). These results did not show the heterogeneity found in experimental investigations.

In the case of constant feed velocity the maximum principal stress over the strip width is higher in the central zone and decreases towards the sides (Fig. 16b). The corresponding density also presents the same profile along the width (Fig. 17b). Results of this simulation are more in agreement with the measurements of the mercury porosimetery (Fig. 7a) and the measured bulk density (Fig. 4). The decrease of the pressure and the density near the sides could be explained by a lesser mass of powder in these zones due to the forced flow of powder.

\section{Conclusion}

The objective of this work was to study the heterogeneity of the properties across the width of the compacted strips of microcrystalline cellulose powders produced by a roll press with a horizontal feed screw. Two experimental techniques; light transmission and mercury porosimetry and a three-dimensional finite element simulation were used in the study. The light transmission revealed periodic heterogeneity shown by darker and lighter zones of the compacted strip, whereas the mercury porosimetry showed higher density at the central part of the compact and lower density at the sides.

The three-dimensional FEM simulation of the roll compaction assuming a uniform feed pressure predicted a uniform maximal principal stress and density along the width. Simulations made by assuming uniform inlet feed velocity predicted a maximum principal stress and density across the width with the same profile: higher values at the central part of the compact and lower values on the sides. These predictions showed similar tendency to the measurement with mercury porosimeter and are in more agreement with the measured bulk density of strips.

\section{References}

[1] J.H. Tundermann, R.E. Singer, Deformation and densification during the rolling of metal powders, Powder Metallurgy 12 (23) (1969) 219-242.

[2] O. Simon, P. Guigon, Correlation between powder-packing properties and roll press compact heterogeneity, Powder Technology 130 (2003) 257-264.

[3] A.M. Miguelez-Moran, C.-Y. Wu, H. Dong, J.P.K. Seviller, Characterisation of density distributions in roller compacted ribbons using micro-indentation and $\mathrm{X}$ ray micro-computed tomography, European Journal of Pharmaceutics and Biopharmaceutics 72 (2009) 173-182.

[4] A.M. Miguelez-Moran, C.-Y. Wu, J.P.K. Seviller, The effect of lubrication on density distributions of roller compacted ribbons, International Journal of Pharmaceutics 362 (2008) 52-59.

[5] Th. Lecompte, P. Doremus, G. Thomas, L. Perier-Camby, J.-C. Le Thiesse, J.-C. Masteau, L. Debove, Dry granulation of organic powders-dependence of pressure 2D-distribution on different process parameters, Chemical Engineering Science 60 (14) (2005) 3933-3940.

[6] A. Michrafy, D. Ringenbacher, P. Tchoreloff, Modelling the compaction behaviour of powders: application to pharmaceutical powders, Powder Technology 127 (2002) 257-266.

[7] I.C. Sinka, J.C. Cunningham, A. Zavaliangos, The effect of wall friction in the compaction of pharmaceutical tablets with curved faces: a validation study of the Drucker-Prager Cap model, Powder Powder Technology 133 (2003) 33-43.

[8] C.-Y. Wu, O.M. Ruddy, A.C. Bentham, B.C. Hancock, S.M. Best, J.A. Elliott, Modelling the mechanical behaviour of pharmaceutical powders during compaction, Powder Technology 152 (1-3) (2005) 107-117.

[9] V. Bonnefoy, P. Doremus, Guidelines for modeling cold compaction behaviour of various powders, Powder Metallurgy 47 (2004) 285-290 (N³).

[10] G. Frenning, Analysis of pharmaceutical powder compaction using multiplicative hyperelasto-plastic theory, Powder Technology 130 (2) (2007) 103-112.

[11] R.T. Dec, A. Zavaliangos, J.C. Cunningham, Comparison of various modeling methods for analysis of powder compaction in roller press, Powder Technology (2003) 130.

[12] Abaqus/Explicit, http://www.simulia.com.

[13] A. Michrafy, H. Diarra, J.A. Dodds, Compaction behavior of binary tablets, Powder Technology 190 (2009) 146-151. 